\title{
CONCEPTUALIZANDO EL BAR. LOS BARES DE SEVILLA EN CONTEXTO
}

\author{
ISIDORO REGUERA \\ Catedrático emérito de Filosofía de la Universidad de Extremadura \\ https://dx.doi.org/10.12795/astragalo.2019.i26.08
}

La desaparición progresiva del bar de siempre condiciona nuevas arquitecturas del bar, que a su vez aceleran la desaparición del bar de siempre. La arquitectura diseño global, que responde naturalmente a una forma de vida nueva, que hay que entender -entre otras cosas porque se impone-, es tan síntoma como responsable de esa situación, mala para unos, buena para otros. En cualquier caso, el bar de siempre es siempre el perjudicado. Le ha llegado su hora sin más. No hay deconstrucción decente alguna. El nuevo diseño del bar es su mortaja.

En muchos casos la arquitectura ha conseguido hoy absorber el espíritu del espacio del bar, convirtiéndolo en un lugar más, de todos y de nadie, de cualquiera. El antaño espíritu del tiempo es hoy en general espacio arquitectónico, de modo que, en el caso del bar, como digo, su espíritu se reduce cada día más a su arquitectura. No tiene otro, ni lo necesita para su nueva existencia y su heterogénea, aunque en cierto modo uniforme, clientela. El bar, como la mayoría de los loci arquitectónicos hoy, es un no lugar o un lugar de nadie, efectivamente. Cosa que no está ni bien ni mal, técnicamente son brillantes y responden sin más al modo de vida de hoy, tan bueno o tan malo como el de cualquier época. En la forma de vida de Sevilla los bares eran monumentos vivos, hoy cada vez más son ya gloriosas ruinas, pero tanto en un caso como en otro, obviamente, interesantes; o esplendorosos diseños sin alma (la de antes).

La arquitectura de hoy es una arquitectura casi imposible porque ha de albergar lo casi imposible: al ciudadano global. (¿Qué es todavía eso, un sí mismo sin lugar o un lugar sin sí mismo? Y ¿qué puede hacer el arquitecto en medio?). Ya no significa la posibilidad de una casa para todos, se ve obligada a pergeñar en cada caso una especie de mercado para cualquiera. 
(De ahí, quizá, aunque sea demasiado fácil la alusión, el éxito reciente del mercado-bar, que no es ni una cosa ni otra, frente al bar del mercado de antes, que era el espíritu, ágora y corazón auténtico del mercado. Buen ejemplo, sí. Los clientes del mercado-bar no son globalitas aún, todavía van de ello. Pero en comparación con el cliente del mercado o del bar del mercado de siempre, un tanto mutantes sí son ya.)

La globalización se está llevando el bar sevillano con una arquitectura de diseño que la mayoría de las veces es igual aquí que en Sebastopol. Sigue esquemas internacionales, de la nueva arquitectura internacional, ultra-racionalista, recargada de sencillez, que ha hecho del diseño la nueva ornamentación delictiva, de la pureza geométrica un laberinto formal, de la funcionalidad un mero sueño estético, que amolda al ser humano a sus circunstancias (las de ella), en la que es el ser humano el que ha de encontrar su sitio, un barroquismo frío, digamos... Y eso, la buena, la original, la esplendorosa, el milagro formal que alucina tantas veces. La adocenada copia casi a ciegas (efectivamente, parece que no ve ni lo que copia) ese espíritu del tiempo enclaustrado en receptáculos inverosímiles, de armonía increíble, inventados en principio en alguno de la docena de grandes estudios o departamentos de arquitectura de este mundo. Esta última, por desgracia, es la normal que puede permitirse el bar del nuevo panem et circenses, es decir, el bar de la cultura de masas realmente existente. Los de antes eran bares del pueblo, ricos o pobres, pero del pueblo.

En la del bar de antes, el "bar", como en la arquitectura de casi todo, no había diseño internacional globalizado. (Además muchos de ellos tienen incluso más de los 50 o 100 años largos que nos separan hoy de la era Loos-Gro- pius \& Co., ella misma anterior al núcleo de la virtualidad, también arquitectónica, el chip... pero tampoco eso importa mucho, la singularidad del bar es más profunda que la razón internacional o el circuito integrado). La del bar era una arquitectura autóctona, más bien casera, no tenía pretensión alguna sino la practicidad más obvia: una bodega, un figón, una tasca, una taberna, una cantina, un mesón, etc. Imaginen ahora esas cosas... En origen no era una arquitectura implantada estéticamente, la función misma imponía los cuatro andrajos arquitectónicos de los que salía como por ensalmo el bar: la tienda, la tienda de campaña, la cabaña de madera, el sótano del vino, la habitación del agua, el cajón de viandas, el ultramarinos, etc., que esos son los referentes de origen de todas esas palabras castellanas para el bar. En origen, digo, luego es verdad que ya se normativiza de algún modo todo y se fue estableciendo una arquitectura típica de mesón, de taberna, de tasca, de chigre, de bodega, que ya por fuera dejaba perfectamente entrever lo que habría dentro. Y poco a poco fueron metiendo mano decentemente los arquitectos.

Pero el origen importa: y ese no fue el diseño artificial, cosmopolita (no había comunicaciones supersónicas), sino el autóctono. Los bares, hoy tradicionales, típico de cada país eran, son todavía, algunos, muy diferentes a los de otro, aunque con un no sé qué de iguales (quizá el propio tipismo en sí mismo, su franqueza antropológica), es verdad. Así que se podría hablar aún de una cierta internacionalidad posible del bar sin enrasamiento global. Internacionalidad pre-virtual y diversidad pre-globalizada: no la monotonía internacional de hoy modelo Starbucks (o nacional 100montaditos) o cualquier otra de franquicia 
aeroportuaria (los aeropuertos son quizá el mejor escaparate de la espléndida arquitectura del no lugar, que decíamos, del lugar de nadie, de lugares cualquiera como sus bares, tiendas, kioscos, dutyfrees y tutifrutis...)

Hay en Sevilla muchos ejemplos de bares de nuevo y bello diseño que echan por tierra elegantemente mi ironía, porque de algún modo siguen siendo sevillanos como sus innumerables tabernas, casas, bodegas, bodeguitas tradicionales... Pero a pesar de muchos son los menos. Los antiguos bares sevillanos conforman todavía hoy esencial y popularmente (para ricos y pobres, decíamos) el paisaje urbano, tanto como referencias imaginarias ineludibles para la gente, como como puntos de llamada del paisaje arquitectónico de la ciudad, son interiores que de algún modo se ven por fuera, hacen calle, no solo por la obviedad de sus dichosas terrazas, que más bien la deshacen, sino por su interior, que es como si no tuviera paredes, los bares son como ollas que bullen espiritualmente dentro y se notan fueran sus borbotones de energía y libertad (a veces con sus ruidos).

\section{(QUÉ ES EL BAR)}

Pero de qué estamos hablando, qué es el bar de que hablo, a todo esto. Hay que comenzar por aclararlo, porque el estar de la arquitectura del bar debería seguir y perseguir su ser. A pesar de todo, es el bar y la gente del bar, su ambiente, lo que da prestancia a la arquitectura, si gusta. En el fondo, la arquitectura no adorna el bar, es el bar el que adorna la arquitectura; si hay buen hermanaje, porque, si no, chirría todo, y si no chirría deshermanado es que estamos en un comedero o bebedero. Si la arquitectura se impone, impone lugar y sitio, como decíamos, la persona entra en rebaño.

¿Qué es el bar? Una cuestión imposible. $A$ un asiduo de los bares e iniciado de verdad en ellos, como yo mismo, le parecerá una tontería, como a mí, conceptualizar algo para nada y para nadie: el iniciado no lo necesita y los demás ni van a entenderlo ni les importa. Pero es además una cuestión difícil por sí misma, nada de lo que diga será el bar nunca, no solo porque las palabras no son las cosas, sino porque ni siquiera habría palabras para hablar de algo que no existe, el bar, hay bares. Así que, si uno se empeña a pesar de todo en la empresa conceptual, no es extraño que las palabras surjan con dificultad, las que surgen. En el fondo no hay necesidad alguna de ellas: basta acodarse en la barra de un bar para sentirse bien en silencio, contemplando desde ahí el panorama, el que ves y el que imaginas, la siempre curiosa gente en torno y la vida y el mundo entero más allá, sin otro horizonte que tus sueños, y el fondo del vaso... Eso es el bar.

Yo me planteo esta cuestión imposible casi por obligación de conciencia. Conozco tan bien los bares, he estado en tantos, durante tantos años y en tantos sitios, que me considero más barero (persona en relación estrecha con el bar, a un lado u otro de la barra, yo utilizaré la palabra, sustantivo o adjetivo, más para el cliente del bar que para el del otro lado) que cualquier otra cosa: la profesión es un modo de perder la vida para supervivir, la condición de barero, un modo de vivir y sentir que vives. Algo he de saber del bar, he de dejar memoria suya... Además, hay más filosofía en el bar que en la academia. Si hay un filósofo en el bar, me refiero, no me refiero al tópico absurdo de la filosofía natural al animal humano, aunque menos a un 
Sócrates-Café... En el bar un filósofo es un filósofo, en la academia es un profesor o un pobre hombre envanecido por sus simplezas. Pensar, lo que se dice pensar, se piensa en el bar o en la cabaña, no en la academia.

Y, bien pensado, no todo es tan nimio en el pensar, se conceptualiza para la teoría, no para que sepa mejor la cruzcampo, ni falta que hace, aunque ayuda. La teoría importa, los casos concretos no son nada sin ella, lo bares concretos no son nada sin el bar. ¿Por qué llamamos bar a algo y a algo tan dispar en cada caso? El concepto lo usamos todos sin enterarnos, aunque a veces surge tácitamente la consciencia y decimos, por ejemplo, que la cruzcampo no sabe igual si no la tomamos en el bar. ¿Qué es el bar, qué es un bar, pues, ese bar que para muchos cambia para bien la cruzcampo que se toma en él, y no en casa, por ejemplo? Buscamos el bar en general, no el Tremendo, el Vizcaíno o el Coronado, pongamos, los tres grandes cerveceros de Sevilla, todos y cada uno son "bar", uno en que no se puede tomar cruzcampo ni nada.

\section{(TÓPICOS ESENCIALES SOBRE EL BAR)}

Temas o trivialidades, da igual, los tópicos, como los refranes, encierran mucha verdad, tan rancia la mayoría de las veces como eterna. En ese sentido, el concepto (la aprehensión intelectual de un objeto) del bar de siempre, es decir la espacio-temporalidad básica y esencial del bar sin más, tiene para mí estos caracteres que expondré en orden sin orden a continuación, sabiendo que sobran y faltan muchos, como es obvio y sucede siempre. Si algo no los cumple no es un bar, es un negocio de inversión en un ramo como podía serlo en cualquier otro.
En el bar no se restaura la homeostasis sólida o líquida del sistema ingestivo o digestivo, se recupera, renueva, recobra, repara el ánimo, el alma, la paz interior. Al bar no se va a beber, menos a comer, se va a algo menos material y perentorio, a buscar vacación y sosiego. Beber es una disculpa, comer una ordinariez. Hablar de los bares como negocios del ramo de la restauración, que es lo que van siendo cada día más, es, aparte de feo, de lo más humillante que puede soportar el bar. La arquitectura del bar no debería contribuir a ello.

El bar es la segunda sala de estar para algunos, casi su verdadera familia, o porque no tienen otra o porque se aburren con la que tienen o simplemente porque se sienten mejor en el bar con los compinches de siempre. El bar es más que un asilo: se respeta a los ancianos, impedidos, raros, ciegos, se les hace sitio, se los acompaña hasta un taburete, se les trata con el normal cariño y la normal guasa de un bar, y ellos responden igual; en un bar no son otredad ya, son normalidad, familia (de bar).

En el bar el alcohol tiene relativa importancia. Si no eres alcohólico (que puedes serlo y no pasa nada, porque mientras te comportes te tratan como acabo de decir, y si no te comportas o bien te dejan de servir, llaman a la familia, piden un taxi, incluso te acompaña alguien a casa si vives cerca, o mal, te echan lo más amablemente que puedan, o te dejes) lo importante no es el alcohol mismo en vena, sino, a ciertas horas y en ciertos momentos, el estado general de leve entusiasmo y poca lógica que te crea, esa vivencia religioso-pagana de antiguo, que deja traslucir el rictus dionisíaco que te invade; estado y vivencia liberadores e inocuos, que no encuentras, si no, en parte decente alguna. "Para bien o para mal, el mundo experimentado 
en completa sobriedad nunca ha sido, ni será, suficiente", efectivamente. (Ese es el mensaje general de Mark Forsyth en su libro Una borrachera cósmica, estupendo.)

\section{(BARRA)}

Lo importante de verdad en un bar es la barra y el cantinero. Casi por ese orden: la fría desnudez de la barra, a ser posible de mármol blanco veteado macael arriba, con un escalón reposapies abajo de madera (una viga de lisura más o menos natural, no un tablón, sobre sencillos apoyos de hierro), en medio fábrica sin demasiado artificio o cemento en bruto más o menos alisado de color al gusto, o sin color, amplia, ancha, enorme, que quepan bien los mostradores de pinchos y no molesten, ya que hay que aguantarlos, mejor tersa y lisa sin nada más que cañeros, botellas de vino en cubos de hielo y vasos de culo ancho, más o menos altos, preparados en fila y pila para el vino y la cerveza, nada de las copas de moda cúrsiles y vacilantes, que no pintan nada en la arquitectura asentada del bar... por ejemplo. Y el cálido humor del dueño, que no tiene arquitectura alguna, aunque un poco de panza y mofletes no le vienen mal.

Fastidia que tanto la palabra "bar" como "barra" vengan del inglés, y que tuvieran en origen una finalidad pragmática de despachar más deprisa, de que el ventero venda más y más rápido, atienda a más clientes a la vez, como en serie, al parecer. Habría que hablar de tascas, cantinas, bodegas, tabernas, mesones, etc., como decíamos, pero el inglés vale hoy para todo y para nada, disuelve el significado al homogeneizar todas sus referencias globalmente, de tal modo que al final queda un ente fantasmal sin caracteres. La barra no es eso, es el centro del bar y su atalaya, el puesto de mando. Incluso mientras el jefe o la jefa charla de lo que sea con quien sea, si se tercia, que es lo normal, dirige la nave: te está sirviendo atentamente a ti, que estás al lado, o te ve que entras por la puerta y, sin haber pedido nada, porque no hace falta, ya te va poniendo lo que quieres mientras te acercas, cuando amarras por fin con el codo en sus dominios, una mirada o un leve saludo mutuos de reconocimiento (complicidad y gratitud) basta.

La barra es esencial al bar, digo (hasta el María Moliner lo deja claro, qué grata sorpresa). Y el cliente auténtico del bar, el de todos los días, el que "ficha" o el que "pasa lista", es el de barra. La terraza, no, que, en España no existe como tal sino después del turismo y de la prohibición del fumeteo. La barra se va perdiendo por la comodidad de los camareros, que la usan de basurero de servicio para los vasos usados, platos sucios y restos de las mesas, el cliente no importa. Y si el bar es nuevo la barra ya ni existe, o no entra siquiera en su arquitectura o se ha diseñado ex profeso para el servicio, de modo que ni siquiera se puede prostituir su oficio de sustento del parroquiano, acodado en ella como manda la usanza. La de la barra es la primera amputación desgraciadísima del bar. Un bar sin barra no es bar.

Y sin embargo la terraza prolifera como el camalote, a pesar de que beber y comer bajo sombrillas y paraguas de Coca-Cola o de Martini, al lado y en medio de humos, gentes, olores, ruidos, bajo la mirada de los transeúntes, esté bien como castigo del fumador y asemeje mucho la zona de penitencia a un abrevadero o comedero de mamíferos humanos. En la terraza se pierde el recogimiento catedralicio y el 
bullicio festivo del bar, ese ambiente esotérico de serenidad de ánimo y de alegre sacralidad dionisíaca de que hablábamos.

La única función loable de la terraza es despejar la barra para los parroquianos, eso sí, en ese sentido benditas sean las terrazas. Son una bendición porque, además de liberar la barra, hacen que no la ocupe ese tipo de gente, que no suele saber comportarse dentro, ni siquiera colocarse en ella: de medio lado, de perfil (para que quepa más gente y el barrero pueda servir entre los perfiles a una posible segunda o tercera fila de clientes dado el caso), un codo apoyado basta, incluso el taburete sobra. Nada de carricoche de niño, niño incluido, padres asentados y abobados en torno a la joya, ocupando media barra, comadres o copadres de charla jarana euforia más que audible, por ejemplo.

\section{(CANTINERO)}

La importancia del dueño (del cantinero), y del camarero, es la

otra pata que sustenta el bar, con la barra. Y también está más que quebrada... Hay tascas familiares y bares negocios de inversión, decía. Estos son los nuevos, de diseño, de futuro, los que gustan hoy y se van imponiendo; lleva a ello inexorablemente un cierto tipo de nueva gente, un nuevo modo de vida ajeno al bar, en el mejor de los casos parece que preocupado nada más que por lo obvio del buen vivir, es decir, por las circunstancias materiales más evidentes de base de la vida, acaparador de eventos y sensaciones sin mayor gracia; sus integrantes ingieren sólidos o líquidos casi simplemente por el diseño mediático que tengan; se deben pensar que están en una cata perma- nente, de esas que ofrecen las grandes bodegas a las masas que las visitan por turnos y tandas. Tan profanos reales como fingidos connaisseurs en sus ademanes, esos gestos suyos de oler y remover el vino en la copa, o la comida en los carrillos, con una mirada de inteligencia arriba al vacío, son gestos ridículos en el bar de siempre. Todo dirigido y manipulado, además, desde arriba, por la moda, nada de modernidad, que la modernidad siempre ha sido revolucionaria, mientras la moda siempre lo contrario. La arquitectura de moda, en este sentido, acompaña perfectamente este ambiente.

El cliente de hoy va teniendo poco a poco el camarero que merece (el dueño ya es anónimo), ni uno ni otro sabe lo que es el bar. Tanto se confunden que a veces parece que quien paga es el que atiende, o debería atender, con mal gesto: el camarero, mano de obra barata cabreada con razón, que se diría que por eso o no por eso toma su trabajo como una pesadez y al cliente como un engorro. El otro, el cliente merecedor de tal camarero, la modalidad mansa de usuario: un sufridor paciente, hasta contento, que ni se entera, o bien porque lo que más le importa es el móvil o el rorro o el charloteo, o le puede la euforia de estar de excursión de finde, o porque es masoquista. Ante cualquier cosa de esas, ni el bar ni el camarero, ni siquiera la consumición, importan tanto, pueden ser cualquiera, efectivamente, como sucede hoy en esos sitios cualquiera, cuya carne de cañón son los advenedizos del bar de un lado y otro. (Exagerando siempre un poco, sin matizar demasiado, que si no al final no se dice nada, no habría por qué repetirlo...).

Poco ya de la profesionalidad que se pedía a un cantinero o a un camarero y de la que hacían gala ellos mismos, en aquellos bares 
cada día más escasos, de los que casi hay que hablar en pasado. (Aunque Sevilla, en general, ha tenido y tiene muy buenos camareros, tipo profesional, competente, cortés, solícito, como Dios manda.) Bares pensados para el cliente, al servicio del cliente, negocios familiares en cualquier sentido, hasta los más encopetados grancafés o cervecerías. No digamos si el bar era un negocio realmente familiar: el patrón o la patrona eran gentes sencillas pero con mucho poderío personal, cuyo saber hacer y amabilidad condensaba un ambiente especial en cada bar; sabían que su vida eran los clientes y los clientes sabían que lo mejor de su vida eran ellos; los buenos materiales líquidos o sólidos importaban, desde luego, como es obvio, y marcaban también diferencias -buenos o menos buenospor su autenticidad, pero hasta las tascas más cutres eran acogedoras si tenían un patrón peculiar, alguien que era él mismo o ella misma, por decirlo así: tan sencillo en teoría pero tan casi imposible hoy en la práctica

Hoy los bares ni siquiera tienen dueño, decíamos, ni en el sentido de señor o señora de la casa, ni siquiera en el sentido de propiedad, cada vez pertenecen más a entidades de inversión. En el bar veías un lugar humano, no un lugar de nadie, decimos, siempre el mismo en mil formas, sin clientes de verdad, ni instalación y mobiliario de verdad, amables, cálidos, nobles siempre, tanto en el bar humilde como en el de más empaque, en los que incluso la choza-tasca es un palacio doméstico y el palacio una cabañataberna acogedora y hogareña. No se sabe muy bien qué tienen esas arquitecturas cálidas, nobles y sencillas, de los bares de siempre, no creo que solo sea la pátina del tiempo. Es algo que yo me tomaría en serio adivinar si fuera arquitecto diseñando un bar...
(Por cierto, que entre esos polos, entre el palacete y la cantina, entre el Alcázar y el Barrio de Santa Cruz, entre la solemnidad que se respira en la basílica del Cristo del Gran Poder y su sencillez arquitectónica, entre esa misma basílica, impresionante por ambas cosas, y por su amalgama, y la campechanía de antaño de Casa Ricardo a la espalda, entre los cofrades del Cristo en su basílica y tomando un vino al lado, entre la Macarena y sus costaleros -a los que en Semana Santa en un descanso en una calle estrecha cerca de la catedral he visto salir con su gorro, no lo olvido por simpático, sudorosos, de debajo de los faldones de las andas, sujetas ya en los zancos, a tomarse un orujo rápido en el barcito que no por casualidad caía en frente, orujo al que por supuesto invitó como de oficio el cantinero, y al segundo yo, con el mayor respeto por su gracia, era muy de noche o muy de mañana, no sé, pero no lo olvido- entre esos benditos polos, digo, está para mí figuradamente la institución de los bares de Sevilla, ése es en cierto modo su "lugar", ni no ni sí lugar, ni de alguien ni de nadie ni de cualquiera: el aire de Sevilla sin más.)

Buena contraposición, para tener las cosas claras, pensar desde este aire en lo que decíamos antes de los bares de aeropuerto, modélicos para los del futuro, imagino, porque hay ya son moda, en los que eres nadie entre nadie, apenas existes, en la cola que tienes que hacer tras cualquiera, en la mesa en serie de mesas en que tomas un café cualquiera, una cerveza cualquiera y cualquier snack (tanta aunque tan poco perfilada mercancía de todo ello hay) como cualquier mindundi (o mendondo, he escuchado en Andalucía) como tú, en cualquier aeropuerto del mundo. 


\section{(MÁS TÓPICOS: SONIDO, BEBIDA, COMIDA)}

No son sones catedralicios precisamente los que se oyen en el nuevo bar de la cultura de masas (en el bar puteado por los no bareros), ni falta que hace, pero ni tanto ni tan calvo: ajetreo de jardín de infancia, alboroto de mujerío vocinglero, también de ruidosos machitos, en pugna mutua general además con el volumen de la televisión (con videos musicales muchas veces, para colmo). Esta desdichada bullanga tiene cierto interés, negativo, porque significa una nueva dilución actual de una particularidad eterna del bar, ante la que aparece mejor su ridículo: la sonoridad. El habla y ruido del bar configura un espacio sonoro único para el diálogo, incluso consigo mismo, un espacio más libre, amplio, matizado, improvisado que el silencio consabido del salón de casa, sala de profesores, reuniones, consejos, etc. Cada cosa para lo que es, desde luego, pero para el diálogo que no busca meramente la propia palabra ni su lógica circular, es decir, no encerrado en su propio discurso e intereses, para la conversación más bien, o sea, para "dar vueltas" libremente a las cosas, con alguien o con uno mismo, el bar y su peculiar sonoridad y ambiente es un recinto privilegiado.

$Y$ ese dar vueltas a las cosas -casi mejor en la mollera, digo, solo y en silencio- conlleva tanto olvido de cosas como invención de cosas: olvidas catárticamente lo que por lo que sea no te interesa o molesta, pero que no puedes olvidar sino aquí, e inventas eufóricamente locuras geniales, racionalizaciones o sublimaciones tan perversas como enternecedoras, de la vida, la mayoría olvidables y vergonzantes nada más salir. Cosas del bar. Se trata de una dialéctica distraída, cuyo tambaleo racional no consigues en ninguna otra parte, solo en el ágora extravagante del bar, en la que puedes vengarte de la razón, más bien de la sinrazón, del mundo de fuera. Sí, el mundo está fuera. El bar no pertenece al mundo. Por lo que sea, es así. (Su arquitectura debería recoger también este esencial aspecto del bar: aislamiento del mundo, aunque sin paredes y hasta prolongado a la calle.)

Eso lo sabe muy bien el bebedor ensimismado... A parte del desastrado borrachín, pobre, el bebedor bebe en el bar, hierático, trajeado, casi como endomingado para una ceremonia; el alcohólico bebe en casa, en silencio, solo, legañoso y abandonado, como recién salido de la cama siempre, porque siempre vuelve a ella tras la cogorza: de la sala de estar al catre y del catre a la sala, en un feedback de somnolencias alienante-narcóticas. El bebedor necesita el vínculo mágico con el bar, la complicidad mágica con el tabernero y la presencia casi espectral -o borrosa, porque poco se entera de ella-, como trasfondo, de los feligreses y su bulla atemperada por la solemne embriaguez, en su negra ceremonia iniciática al bendito absurdo del suicidio lento y húmedo; o simplemente a la conciencia del paso inevitable de la vida a su final, que el bar contempla y refleja en ti día a día, año a año. El bar es la capilla en la que el bebedor exorciza los demonios de las ilusiones, sublimaciones y mentiras de la vida, muchas veces creadas en el bar mismo, es verdad. El alcohólico casero ya está muerto, al bebedor del bar le queda su tácita ceremonia pública de despedida, un velatorio anticipado. Bueno, pero no hace falta ser bebedor ni alcohólico...

Bebedor o no, mucho o poco, a los bares se va a beber. En realidad, a los bares no se va, o no se debe ir a comer, que es muy grosero frente 
a lo que digo. El bar no es un restaurant con todas sus ceremonias para olvidar lo que se hace en él... Al bar se va a pasar o a perder el tiempo a gusto con un vaso, pote, chato, caña, catavinos. Con un corto, un zurito o un chiquito, basta, son una excusa para levantar el espíritu, no para abotagarlo con la tripa llena. En los bares de Sevilla se está comiendo siempre, es verdad, como en los de mi tierra (solo que en éstos, los de León, la tapa es gratis), pero se perdona, porque se trata de tapas y dicen que sin la tapa el vino o la caña no entran, o que el alcohol se sube demasiado. Bueno, se disculpa porque es a causa del espíritu del líquido por lo que se toma la materia sólida, y no al revés: se come para beber o para beber más o emborracharse menos, eso está bien. Se come para acompañar la bebida, no al contrario. Al menos hay que ser conscientes de ello, que quede claro. Y si es por la tapa exclusivamente por lo que se va a un bar, como sucede cada vez más, en fin, hay que soportarlo, aunque no es lo suyo esa avidez tapera, que asquea un tanto si te toca un tapero así al lado, aunque sea un amigo. La tapa debía ser, como era, un mínimo pincho para dar cierta alegría a la bebida: trocito de pimiento rojo en conserva, trocito de anchoa y aceituna empalillados, o un menudo detalle cualquiera pinchado con un palillo (basta una aceituna, decíamos), que se tira con la servilleta con que te limpias para no ensuciar el vaso y pringar la bebida (cuanto más gruesa sea la alfombra de palillos y servilletas usados en el suelo, mejor, más mullido, ya se sabe). Lo demás es anecdótico en el bar, incluso el lujo de las ricas "gildas". Pero dejemos esto, es mejor también, que sobre todo en Sevilla la anécdota en este caso es ya categoría.

$\mathrm{Y}$ a Sevilla vamos.

\section{(SEVILLA, POR FIN)}

Sevilla es otra cosa para casi todo. Eso es algo que hay que tener para todo en mente. Los bares sevillanos son otra cosa, incluso que los andaluces, que son ya de por sí distintos del resto de los patrios y no patrios, y entre sí: no son lo mismo los gaditanos que los almerienses, por ejemplo, y en medio, todos los demás, pero los sevillanos quizá sean incluso más suyos, y no solo por las paredes, ni solo por su profesionalización para el turismo. Por “sevillanos" simplemente, sea lo que sea eso, mi nuevo tema imposible ahora, el "bar sevillano".

Sevilla se abstrae del mundo en sus bares. Pero de verdad. Enrollados en su conversación y aparentemente alegres y distraídos, los sevillanos pasan del mundo en el bar. Gentes siempre joviales, a veces parece que estén de fiesta siempre, quizá no los mismos, pero sí los bares, que no se vacían nunca. Aunque para fiesta de verdad tengan el salto mortal de la Feria, allí no están tan alegres, más preocupados de ver y ser vistos, más artificiales, más melancólicos, ahítos de finos, aburrimiento, cansancio y vanidad muchas veces: no han de verte ajado, sino espléndido.

El deje sevillano resuena afelpado en el bar, aunque se hable alto no hay tantas estridencias infantiles, mujeriles o varoniles como en otras partes. Contribuye también a ese ambiente la euforia despistada y tenue del inevitable guiri, siempre educado, más que el turista patrio en general, más bulloso; un tanto bobalicón, boca abierta de admiración o desconcierto, pero solo porque está de turisteo: en su ambiente patrio, de bobalicón no tiene nada, como veo siempre por el extranjero, donde el guiri y el bobalicón soy yo. Pero eso no cambia 
las cosas... Lo malo o lo peor de guiris y turistas no son ellos mismos, sino los negociantes del bar, que suben precios y bajan calidad a su costa, arrasando zonas enteras de bares, antes buenísimas. Es normal que el visitante no tenga el gusto del que gusta a diario lo que sea y que se entere menos de todo.

Hay un moderado contento general contenido un tanto artificioso, que tiene que ver quizá con la ligereza del alma sevillana, pura estética, y en el que esta torpe presencia del omnipresente turista (extranjero o patrio) tampoco molesta tanto como lo hace por los más adustos bares del norte. No se puede hablar de molestar, y desde luego al dueño no, está claro, pero el turista siempre incordia un tanto al cliente asiduo en sus bares de siempre, en los que hace falta tiempo y tacto para que te admitan de verdad en la logia, tras años quizá, en la tácita conjura de la parroquia, y si no, siempre serás un extraño en ese simpático contubernio esotérico. $Y$ llega el guiri y le tratan de inmediato estupendamente, como a un extraño, claro, pero él no se entera, mientras tú contemplas pensativo el panorama un tanto mosqueado, divertido, irónicamente melancólico: lo que es la vida...

En Sevilla los camareros son profesionales la mayoría, insinuaba (recuerdo con gusto en este sentido los de La Bodega de Alfalfa). Por eso, con su buen saber y estilo, son capaces de encajar lo diverso en el ambiente único de cada bar y de algún modo hacen sentir de verdad casi cliente habitual de la casa al menos al guiri patrio que perciben como barero asiduo. Es la complicidad universal del bar sin más.

\section{(PAREDES Y AIRE)}

Los bares de Sevilla no tienen paredes, ocultas tras cuadros y fotos, inexistentes por abarrotadas de ellos. (Y por más cosas.) Pero curiosamente eso no los empequeñece, les da como un aire de saloncito palaciego, o de salón de casona o cortijo, recargado pero espacioso y despejado, casi vacío, por muy lleno que esté: esas no-paredes se comen a la gente, son un entorno inexistente pero demasiado abigarrado formalmente, no solo para fijarse en la gente, sino para que ella misma emerja claramente de él. Con sus cientos de ojos o ventanas artificiales, las paredes te mantienen preso en la red del bar, todos sus cuadros y fotos se reflejan hasta hundirse en ti cada uno con su detalle, te miran; son ellas las que te observan, te vigilan, añadiendo a la que crean tus propias miradas y observaciones una absorbente atmósfera de tensión extraña. Esa que bulle dentro y se nota fuera, decíamos, condicionando incluso el paisaje urbano.

La pared no es pared, no cierra o limita un espacio, deja pasar el bar a la calle, se abomba a punto de explosión o desaparece en el imaginario del transeúnte que presume qué hay dentro. Ni dentro ni fuera existen las paredes. Su espesa verticalidad arquitectónica es superada y traspasada por el espíritu del bar y de la ciudad llena de focos de poder de gracia y sabiduría ancestral, nódulos de vida humana concentrada, como corazones palpitantes, los bares. Como antaño las iglesias... Porque otro tanto sucede todavía hoy con las iglesias de los cristos y vírgenes de la devoción sevillana. No hay otro mejor ejemplo de burbuja de espíritu después del bar que la iglesia, los demás monumentos se han vuelto turísticamente convencionales y la feria resulta demasiado obvio que 
no tiene paredes sino tenderetes, tanto la feria como los toros son demasiado poco íntimos como para tener paredes inexistentes. Y, bien mirado, también podríamos decir que Sevilla entera, en general, a pesar de su arquitectura robusta, no tiene paredes, su aire las puede. Aire en vez de paredes.

(Si piensas en esto en un bar sevillano, como yo hago, la manzanilla en el Barbiana o el vino de naranja en La Goleta, o los dos en Álvaro Peregil, o la cruzcampo en el Tremendo, por decir algo, saben mucho mejor, que es lo que importa: saben, huelen mejor, con ellos inhalas privilegiadamente en tal circunstancia aire de verdad sevillano.)

El aire es la gran arquitectura sevillana. Etérea, sí, pero da igual, o da mejor: es el principio constructor del sentido de todo. De la consistencia de Sevilla como sí misma. Una arquitectura de aire es Sevilla. Su arquitectura ideal, me refiero, porque, como acabamos de decir, la real, la clásica -como ejemplos máximos el clásico renacentista apabullante Cinco Llagas del XVI o la clásica barroca imponente Iglesia del Sagrario del XVII-, es robusta, aplastante... Sí, pero etérea. En Sevilla no aplastaría ni el Monasterio de El Escorial, por decir algo. (Algún malvado pensará por asociación en el Valle de los Caídos, tampoco ese horror hortera, impensable en Sevilla, espantaría el aire sevillano.)

No sé si Sevilla tiene un color especial, probablemente, porque en Sevilla todo es así, pero sí un olor especial, desde luego, a azahar, a naranjo agrio, el aroma de abril en Sevilla, aunque la ciudad entera huela también a Semana Santa esos días de Pasión, no sé qué olor es más especial. El olor de Sevilla más que especial es sutil. También sus bares, naturalmente, tienen un sabor muy especial, que no solo pende del gusto de sus tapas, desde luego. Pero lo que posee Sevilla es más bien un ánima muy especial, un ambiente, una atmósfera, un aire, como los que percibes en la Plaza de San Lorenzo, por ejemplo, mi preferida, cuando un día de un mes cualquiera, no digo ya en Semana Santa, bajando Santa Clara, pasas el Eslava y contemplas a la izquierda de improviso el rincón mágico de Parroquia y Basílica. Sevilla tiene un aire muy especial que luego se concentra en sus bares y traspasa sus inexistentes paredes hasta la calle, y vuelta; bares donde, con la gente, entran esos frágiles aromas e impregnan la atmósfera que sus bultos físicos crean dentro y sacan fuera en una especie de feedback que crea la materia de ensueño de la que está hecha Sevilla.

Sevilla es otra cosa, decíamos, o lo que es lo mismo: Sevilla es Sevilla (no todo es o tiene un sí mismo y menos sin parangón). Desparramada y presente toda ella en cada rincón, esta ciudad tiene una personalidad única incluso entre las ciudades más únicas: un aire, un olor y un sabor intensos, pero demasiado leves e indefinidos para aprehenderlos conceptualmente, como me gustaría. Se quedan en metáfora, qué vamos a hacer. Aire y sabor, olor también cómo no, que me contento con percibir privilegiadamente (no hace falta patear tantas calles a lo tonto) en los bares donde se mueve su gente. $\mathrm{O}$ en las iglesias...

\section{(BARES E IGLESIAS)}

Ya lo insinuaba, entre bares e iglesias anda el juego del aire (olor y sabor) en Sevilla, por lo menos eso es lo que parece a un visitante como yo. Juego que en España no sería extraño, si se piensa, por ejemplo, en la tradición popular de 
"tomar el blanco" después de la misa dominguera, cuello y puños de camisa almidonados, traje y corbata: un domingo como Dios manda -nunca mejor dicho- también es cuestión de bares y vinos. Pero esa inocente domingada tiene poco que ver con el imaginario sevillano de iglesia y bar, creo...

En principio ya es muy cómodo y común que te den la referencia de una iglesia para localizar un bar (y al revés, aunque sorprenda). Por ejemplo: frente a la iglesia de San Benito, la Chicotá, y al otro lado de la acera, Las Cabrillas (dos bares clásicos de caracoles, o de caracoles y cabrillas, para quien los distinga.)

Pero además parece que se arropen mutuamente iglesia y bar. No hay quizá mejor ejemplo de ello que la citada Plaza de San Lorenzo y aledaños, los alrededores del rincón más mágico de Sevilla entre la parroquia y la basílica, insisto, el entorno del Cristo del Gran Poder (basílica que impresiona, sobrecoge en su sencillez, el talón desnudo del Cristo la llena toda, es como el punto angular y el núcleo de fuerza de esa especie de planetario arquitectónico del aire sevillano de que hablamos o de nave espacial que lo surca) y de la Dolorosa más antigua de Sevilla, la Soledad de San Lorenzo, con su espadón clavado en el corazón, mirando la corona de espinas del hijo en sus manos, con su makeup dramático, digna, elegante en su dolor, toda una Señora en su solemne enorme alcázar.

El desconsuelo elegante de esa pareja torturada llena el aire de la zona y sus viejos bares. Sobre todo, como evidencian sus no-paredes parece que consagradas, Casa Ricardo, bar de hermanos y hermandades, cuyas croquetas son casi tan antiguas como la Virgen, más desmejorado cada vez que vas, pero estupendo aún; si hay sitio no puedes dejar de pasar un rato con un vaso vino, con croquetas o sin croquetas, imaginando la Sevilla en que estás de hecho, no sueñas, y sobre todo el rincón que allí te da la espalda. Donde no se nota esa elegancia, sino por su ausencia, es en el afamado Eslava, en el que da hasta cierta grima ver cómo pugnan en cola guiris y cristianos por conseguir un montón de tapas -que apilan en un plato, ávidos-en la barra y cómo las engullen y glotonean, satisfechos por su hazaña, en alguna escurrida mesa de la angosta terraza. No extrañaría que a esta escena le diera esquinazo adrede el paredón de la soberbia parroquia...

El Sardinero, pared con pared al Gran Poder, parece que lo mejor que tiene ya es eso, porque, a pesar de ello y de su tradición cofrade, bética y comunista, a pesar incluso de su terraza en el rincón mágico (lo estropea), tampoco corre demasiado aire sevillano por él, y no solo porque esté abarrotado de gente tras la renovación. Por la Bodega San Lorenzo sí corre el aire y el sabor y el olor de Sevilla, bar todavía auténtico, hermoso, pequeño, agradable, tapas clásicas y buenas, de antes, sabor de siempre, clientela maja, compuesta, a esta no se le nota en los ojos el ansia arrampladora de tapas, pero sí que sabe más de ellas: picadillo de atún fresco con cebolla, aceite y salsa de tomate de verdad, por ejemplo, la tapa que llaman "el repetidor"; atún en escabeche, sardina ahumada, etc.

No es fácil de olvidar, para bien o para mal, el maridaje entre iglesias y bares en toda Sevilla. Ese regusto de San Lorenzo, de Santa Ana, de la Macarena te persigue por doquier, pues por doquier emerge inesperadamente la torre o la cúpula de una iglesia, que te lo recuerda, o te pegas de sopetón con ella... Efectivamente, en todos los bares, buenos y malos, de San Lorenzo se nota de algún modo, creo yo, 
que soy casi turista, la sombra benéfica de la parroquia o de la basílica al lado. También en el entorno de la iglesia Santa Ana, por ejemplo, preciosa, la más antigua de Sevilla, se siente la inmediatez de esa catedral de Triana en los bares estupendos, sevillanos, que la rodean, que también me recuerdan ese maridaje de que hablamos: el Santa Ana, la Plazuela, el Bistec... y en un derredor más amplio: hasta la freiduría Reina Victoria por arriba y el bar La Viña por abajo.

Igual o más en el entorno de la Macarena, de la que me resulta imposible decir algo más que su nombre, pues lo significa todo en Sevilla. Rodeando su basílica, en este barrio de San Gil, hay bares magníficos, como La Cantina del Mercado de la Feria, popular y buena donde las haya, todavía bar de mercado, buenas tapas y auténticas, tortillitas de camarón, pescadito frito y frutos del mar, con un rinconcito de terraza precioso y acogedor en torno a un ángulo de la pared de la iglesia Omnium Santorum, por cierto. O como el Tendido 11: mistela y carne mechá, caracoles, toros y vírgenes, techos altos, mesas y sillas plegables de madera, todo como en penumbra, carteles de toros amarronados por el tiempo; es curioso: aunque su nombre evoca el tendido más torero de ella, no está en los alrededores de la Maestranza, sino en el lateral del Parlamento; esa vecindad es lo único que amarga el sabor, el olor y el aire de este bar, a mí, claro; no desde luego el impresionante edificio renacentista que hoy alberga a los políticos, el antiguo Hospital de las Cinco Llagas; lo que amarga el gusto de este bar, estupendo, él no tiene culpa, es que haya que añadir la política a la virgen macarena y al gran arte del toreo, que lucen en sus paredes, y al gran arte arquitectónico renacentista sevillano del XVI; todo eso se nota de algún modo en esa vieja nave del Tendido 11...
Todas las cañas saben buenas en Sevilla, pero recuerdo desde muy antaño la proverbial cerveza de la esquinilla de El Tremendo (junto a la curiosa iglesia de Santa Catalina, sede de hermandades, recién reabierta), arte de tirar y hacer espuma, a su modo, al modo sevillano, porque las cañas de Cruzcampo, en general, no saben en ninguna parte como en Sevilla, buenísimas; en el Tremendo, pero también en el Vizcaíno y en el Coronado, la trinidad cañera de Sevilla, que yo sepa...

Se cansa uno de enumerar y describir bares y consultar notas. En casi cada bar sevillano hay una foto, muchas fotos, montones de fotos, de la virgen o del cristo más próximos, comiéndose las paredes. Un ambiente eclesial en cierto modo, pagano, pero no tanto, más o menos festivo. En fin, hay miles de bares buenos, típicos y todavía legitimados por el uso autóctono, salvables, pues, en Sevilla, cerca y menos cerca de una iglesia, cerca siempre, de arquitectura de capilla con barra. Eso es.

Resulta imposible conocerlos todos en una vida, diría, y menos para un foráneo. Lo mejor es que un sevillano te guíe en esa jungla, pero también se pasaría la vida, la suya y la tuya. Así que lo mejor, realistamente, es recorrer al tuntún los que puedas y dejarse de coñas; o, seriamente, hacerlo por rutas, siguiendo un buen itinerario de un nativo barero (iglesiero no hace falta, en las iglesias te fijas tú): la de los caracoles, la de la pringá, la de los garbanzos, chicarrones, la de los toros y rabo de toro, montaditos, jamón, etc. Como la de las iglesias y su entorno barero, que acabamos de pergeñar nada más, puesto que hay muchos más entornos eclesiales bareros en Sevilla. Me parece a veces que los sevillanos sienten la misma devoción, veneración, afecto, hasta sano o santo 
cachondeo, por sus cristos y vírgenes que por sus bares...

\section{(ENTRE BARROCO Y ABADÍ)}

Todo en Sevilla es un festival del exceso contenido (contenido por la pesadumbre), tanto de lo barroco (abigarrado, desbordante) de sus iglesias, pasos y cofradías, como de lo barroco de sus bares y feligresías bareras. Lo barroco impregna Sevilla: arte preciosista y decadente de la Sevilla del XVII, que iba perdiendo en aquel tiempo, tanto de penuria como de exceso, las prebendas de ciudad adelantada y puerta de una América en desaparecimiento, de la Sevilla que compensaba con oropel las pérdidas del oro americano; con una religiosidad un tanto llamativa, neurótica, impuesta por curas en huida hacia adelante, tras perder también sus privilegios en las misiones americanas, pero no otras prebendas interiores (donaciones, rentas): bombásticos templos, vírgenes y cristos hermosos y dolientes para el pueblo hundido, que al final era el que sufría todo, al que no quedaba otra que el consuelo de la sublimación barroca, impuesta sin saberlo; o un fervor forzado por un racionalizador sarcasmo, en los más conscientes de la decadencia, por la risa desesperanzada ante la consunción de uno mismo. Sevilla se consumía entre oropeles sublimadores, ironías y cachondeos desesperados, qué remedio. De ahí su gracia trágica de hoy, la que se respira en la alegría de sus bares. Y en el tan dejado como elegante carácter burlesco sevillano. Ánimo melancólico, amargura más que melancolía, desgana existencial, colmillo retorcido también, en el fondo del alborozo y alboroto de la vivacidad de sus bares.
Sevilla es barroca, nació como es cuando iba muriendo y vive como agonizando siempre; un fondo, sí, de la serenidad, equilibrio y lógica clásico-renacentista del XVI, que distingue sus edificios más importantes en la época de su importancia; pero más bien drama, teatro y exuberancia barroca de su decrepitud, aunque con la coña amarga del poder y el trapicheo perdidos de las grandes épocas del Imperio, cuando por Sevilla entraba toda riqueza (que era muchísima) aunque fuera para largarse, tal y como llegó a Sanlúcar, por los Pirineos para pagar en Europa guerras de familia o de religión u otras diversiones de los Austrias germanos, que no llevaron a nada y que dejaron a los españoles fuera de la modernidad esplendorosa de ahí arriba: ni hubo inversiones, ni industrias en España, nada más que pícaros e hidalgos descamisados, sobrevivientes. Nido de maleantes y pícaros a la espera de hacer allí o aquí las américas, ratonera y hervidero en explosión, aquella Sevilla en la que se roba para poner velas a santos o encargar novenas a vírgenes, hampa y religiosidad unidas, contrarreforma y picardía (ver Rinconete y Cortadillo, por ejemplo). Caldo de cultivo para el oropel desequilibrado, retórico, engañoso, caprichoso, recargado, excesivo, del barroco incipiente.

Sevilla barroca, alocada y de guasa, desenfrenada tanto en la blandura, suavidad, como en el dramatismo (niños harapientos pero felices de Murillo) de su arte del XVII o XVIII; exageradamente expresiva (pinturas de Valdés Leal del trascoro de la iglesia del Hospital de la Caridad, la propia personalidad de Miguel de Mañara)... consciente de esa pomposidad impostada y de sus raíces decadentes, con el rictus amargo e irónico de la elegante sobriedad perdida, tanto de épocas recientes clásico-re- 
nacentistas cristianas, como de épocas remotas de taifa musulmana rebelde, con una corte refinada, sobre todo en el último tercio siglo XI, en tiempos de Al-Mutamid. Todo eso pesa en el alma de Sevilla, en su aire.

Esa elegancia clasicista del antiguo Hospital de la Sangre o de las Cinco Llagas citado, por ejemplo, y ese refinamiento abadí, del que pocos vestigios quedan en el Alcázar, qué pena, la contención y decorum clásicos y la geometría inefable de la arquitectura perdida abadí, cuya armonía y dimensiones creo que puedo hasta evaluar -con un radar quimérico o como si yo mismo fuera un murciélago que sobrevuela la escena- por los ecos de los bellísimos poemas de Al-Mutamid, sonando, digamos, por el aposento donde aparece el copero en noche oscura, que citaré a continuación... circunspección clásica y numen abadí, digo, permanecen en el fondo de exceso del carácter barroco del sevillano: una seriedad extraña que tiñe sus jolgorios, una sombra que corta de vez en cuando su sonrisa, un señorío que supera su proverbial gomina, estiramiento, un modo de estar del sevillano tanto en la vida como en sus bares que los hace únicos. Refinamiento abadí, solemnidad renacentista, jolgorio barroco en el alma y el bar de Sevilla.

Al sevillano le gustaría, como a todos, pero a él más, que lleva sangre abadí, que en el bar de hoy se le sirviera como describe AlMutamid en su poema sobre "el copero, la copa y el vino", más bien la "copera”, imagino, o no: "Apareció, exhalando aromas de sándalo / al doblar la cintura por el esbelto talle. / ¡Cuántas veces me sirvió, aquella oscura noche, / en agua cristalizada, rosas líquidas!” Bellísimo, digo, lástima que no fuera en el bar de palacio; curiosa expresión, por cierto, porque los palacios, menos en aquel tiempo, no tienen bar, al menos como el de que hablo, aunque los bares de Sevilla, bien pensado, tienen algo de palaciegos, ya decíamos, quizá sea por esto: porque esperan en ese atuendo que este copero ideal vuelva algún día para servir en ellos y porque sus clientes esperan ser servidos allí algún día así, y unos y otros aguardan, en trance, agua cristalizada, rosas líquidas... Ilusiones, pero su trasfondo tiñe metafóricamente el alma sevillana, aquél aposento cristal oscuro es el lugar propio suyo, la arquitectura íntima en que aparece el gran copero a sosegarla. $\mathrm{O}$ al menos puede servir para explicarla un tanto.

\section{(MODO DE SER SEVILLANO)}

Hay un modo sevillano de ser en el bar que es el modo de ser sevillano mismo, como venimos insinuando. Juega entre varias cosas, siempre en el contrapeso triple de que hemos hablado: el absurdo, con el que se corta el discurso a discreción y voluntad, cuando sale, sin más, más que cuando resultaría lógico y cortés; la risa fácil, pero a medias, contenida, como un fonema más en el discurso, entra dentro de su gramática; la exageración leve e ingeniosa (no la bruta, aunque ocurrente y graciosa también, bilbaína, por ejemplo); la superficialidad o intrascendencia despreocupadas, conciencia de que los temas del bar, como cualquiera, tampoco van a solucionar el mundo; con esa especie de frivolidad se cachondean de casi todo, sin maldad pero con malicia.

Los sevillanos no son graciosos, comparándolos con la mala leche de los granadinos puede ser, pero a esa malafollá los sevillanos no llegan, lo que tienen más bien es un sentimiento trágico de la vida. No recuerdo si esto era lo 
que gustaba a Lorca, lo trágico pero luminoso y abierto de los sevillanos, frente al mal aire cerrado y reconcentrado de sus paisanos, pero imagino que sí. Graciosos son los gaditanos, que no se ríen nunca. Son serios por irónicos. Los sevillanos no son irónicos, son oscuros, de humor misterioso, opaco. No se mofan espontáneamente hasta de su sombra, como los gaditanos, o puede que sí, pero con retranca, es decir, para burlarse disimuladamente del otro. Aparte de que siempre les afecta algo, siempre tienen un tope: su cristo, su virgen, su betis, su triana, su bar, ellos mismos, etc. Y eso no se toca, de eso no se hace chiste.

Los sevillanos no son personas alegres, sino bulliciosas. Les corta la gracia, la alegría, les agua la fiesta, digamos, ese fondo de seriedad y amargura de siempre, que señalábamos, como el de sus cristos y vírgenes, cuya hermosura y tragedia, estética y drama, farol y negrura, como los de los pasos en los que exhiben descaradamente todo ello por Sevilla, es parte del agua cristalizada, transparencia mate, del alma sevillana.

¿Por qué esa gravedad triste en el fondo de su risa? Porque la vida pasa con la conciencia de que pasa, ellos todo lo hacen para que pase bien, eternizándola en momentos leves, para que pase sin demasiado dolor por la conciencia del pase, pasando sin pasar, digamos, un pasar de la vida que es la propia vida, el propio estar y sentirse en ella. En el fondo no pasan de nada, saben que es la vida la que pasa de ellos. Ver pasar el tiempo con un vaso en la mano, alegre y triste... Todo el oropel palaciego de sus bares es como el de una espléndida sala de tanatorio, los despojos están siempre al lado, sobrentendidos, pero sólo ellos dan sentido al edificio entero...
(EN EL PECATA MUNDI)

Ello me recuerda otra ironía fúnebre: hablo con un poeta sevillano en el Pecata Mundi, donde te recibe un azulejo cadavérico por fuera y otros muchos objetos inquietantes dentro; un bar lleno de guiris, pero en el que no desdicen demasiado, ni de la compostura del cliente de siempre ni de la idiosincrasia del bar mismo. En otros desdicen hasta desdibujar el bar, en este creo que no. El poeta, un asiduo de los bares, me decía ante mis preguntas sobre ellos, lo recuerdo en ráfagas de verdadera sabiduría: la ciudad se está engolfando porque los bares se están quedando sin barras; se ha perdido el "leñazo" mañanero del coñac o anís con el café; los bares de Sevilla no son bonitos, tienen sabor; de siempre los bares de copas en Sevilla sirven copas muy mal, pero las bodegas son maravillosas, su vino genial; siempre tienen demasiada gente los bares, incluso a la puerta, fuera, donde precisamente el poeta escuchó a alguien: "yo vivo encerrado en las calles", y, además de enfatizar el bello oxímoron, comenta con lógica: es que en Sevilla las calles son bares y los bares son calles. (Claro, por eso no tienen paredes.) ¿Dónde están calles y bares, entonces? Ah, en el aire de Sevilla.

Puede que "aquí abajo", en Sevilla, sigue el poeta, hubiera terrazas antes, como la de Sierpes donde se sentaban Rafael el Gallo y Belmonte en silencio durante horas. Pero en Sevilla, en general, a la gente le gusta menos sentarse que en otras partes, nos gusta estar de pie en los bares, ya nos sentaremos a comer en casa. Gusta comer en casa, efectivamente, pero, si se da el habitual caso, el sevillano prefiere desde siempre comer de pie en la barra, ir de tapas de bar en bar, que sentarse en una mesa 
de restaurante, menos en una terraza. El boom de las terrazas nace con el turismo y el tabaco, tercia un asturiano amigo, dueño de un bar allá arriba, y afirma rotundo: ¡el bar está en la barra o en la calle y de pie! En el sur sí, siempre ha habido terrazas, parece que replica el poeta sevillano, pero añade: aunque "la gente de bien" nunca íbamos ni vamos a ellas, eso ni se plantea. La gente de bien es la del bar, naturalmente. Ya imaginan qué placer para mi escuchar estas cosas precisamente en Sevilla, donde todo este imaginario se va diluyendo a velocidad Mach. Pura sabiduría barera de la buena, de la mejor.

\section{(EL GARLOCHÍ)}

La Virgen no sé, pero al menos Dios está en todas partes, dicen, también debe estar en el Garlochí, pues, a pesar de que tantos guiños podrían amedrentarlo, espantarlo... Todo un tapiz de vírgenes, cristos, terciopelos, las paredes, guiris entrando y saliendo sin parar, la Duquesa de Alba, en pintura, sobre un extintor de incendios y bajo la falda de una Virgen, en la esquina derecha de la barra bolsas de "sangre de Cristo", al lado de unas transexuales espléndidas tomándose en copa esa mezcla de champán, güisqui y granadina. Siempre he ido de noche. Transgresión festiva de los cánones de la religiosidad eclesial, tanto la imita por fuera que sus ritos, los ritos del bar, adquieren cierta sacralidad, profana sin duda, pero consagrada: tomar un vino allí te produce un cierto hormigueo transubstancial. (Y el ridículo de Uma Thurman, vestida de Dolorosa, te horripila, como si se tratara de un auténtico sacrilegio, aparte de que está horrible, no me extraña; la culpa la tiene el simpático dueño, que además se dice muy creyente: que me perdone, pero la chabacana manía, la gracia demasiado obvia, de vestir de dolorosas en su bar a quien quiere, es un pecado objetivamente imperdonable, aparte de subjetivos perdones, cabrea sagradamente, como al propio Cristo el templo profanado.) El Garlochí, a pesar de su coña, no es un mero bar, debía tenerse un respeto a sí mismo, emana extraña religiosidad por todas partes; y en ese sentido es más también que una iglesia, hoy sin alma y vacías todas: lo contrario de este "corazón" de la Alfalfa, con alma y repleto de fieles.

El Garlochí es una capilla civil recargada de imágenes religiosas, antes local de marginados, me dicen, ahora también en cierto modo, con guiris en masa añadidos, pero todos convenientemente acomodados. Tampoco aquí los guiris estropean nada, el decorado los puede, puede a todos, a no ser que estén borrachos o muy bebidos y no se enteren de nada. La barra con casullas de cura de mantel bajo el cristal. Pomposo baldaquino terciopelo granate sobre ella, en el rincón de la pared más de mil detalles no memorizables. Curioso que gente de sexualidad tan variada se sienta bien rodeada de tantas vírgenes. Hay guiris y turistas en general, que entran en manada y se marchan rápidamente, sin más, como si ya hubieran visto otro monumento más de la guía y quedaran muchos. Pero hay que resistir allí hasta aburrirse, como en las iglesias, hay que seguir la santa misa hasta que acabe, para ganar el cielo.

Encuentro otro poeta, este desolado, que va buscando faros en la noche y en su embeleso imagina que son las luces de los bares, entra en este y se viene abajo toda su aventura, ya no sabe qué pensar de nada: este faro desconcierta al máximo, te introduce en una vorágine procelosa en vez de orientar en la noche oscura 
del alma. Todos hablan, ese runrún eufórico y el barroquismo exasperadamente hortera cansa bastante al poco. Entonces, ya es un templo de nada y de nadie. ¿En qué queda? En algo entrañablemente cutre.

El Garlochí es de una tristeza conmovedora, histriónica, un sarcasmo del alma sevillana. Por eso inquieta. Y es el arquetipo estridente, estrambótico, estrafalario, de coña, de la simbiosis sevillana de iglesia y bar: festiva y amarga. Cuando es el caso, no solo en el Garlochí, el sevillano reconoce el absurdo en el que lo pasa bien, de vez en cuando una sonrisa leve cruza por sus risas, decíamos. Parece a veces que es consciente del absurdo mismo de pasarlo bien, y de la sinrazón añadida de pasarlo bien en un bar. Y es que en un bar se pasa bien por algo más que por comer y beber, que por llenar la panza o trastornarse la cabeza. Pero en el fondo no se sabe por qué. No es razonable pasar el tiempo porque sí, sin más. Y que además esa sea la razón suprema de pasarlo bien. Eso es lo inquietante del bar, casi un misterio zen a pesar de todo su bullicio y ajetreo. El Garlochí es un grandilocuente decorado triste-festivo para este absurdo inevitable, una grandilocuente escenografía del obligado pasar de que pase el tiempo.

\section{(FINAL)}

Me despido en Camas, en el barrio de La Pañoleta, y naturalmente en las Bodegas San Rafael, casi tan famosas como Curro Romero, es un pecado decirlo, me da cosa, pero cada uno tiene su duende, el duende sublime y majestuoso del toreo y el duende popular, modesto y en cierto modo también grandioso de la bodega. Tradición torera de La Pañoleta, con su desaparecida placita, hoy bajo la autovía de Huelva la pobre, donde se forjaron toreros como Curro Romero (que se vistió en ella de luces por primera vez el 22 de agosto de 1954) y parece que Paco Camino, nada menos. Nunca agradeceré bastante a nuestros amigos que eligieran esta bodega, que no conocía, para despedirnos. Es espléndida, toda una vivencia ya el entrar e ir a su barra a hacer cola para pedir, mientras contemplas el amplio interior: cubas viejas por doquier, hasta colgadas del techo sobre el mostrador, vírgenes, cristos, toros y toreros por todas las paredes. Toda una vivencia también recoger después, sin esperar mucho, el pedido en un papelón como de estraza modernizado y llevarlo a una mesa de tijera con sillas de tijera bajo el pórtico. Está buenísimo todo, sabores muy populares, pero estupendos: aparte de gambas o patas rusas, carne de caballo (sancochada), chicharrones, embutido, quesos, vino de pasas, mistela, el famoso "ligaíto" de mezcla. Olor húmedo y viejo a bodega, taberna, tradición, etc. y un resumen popular de toda Sevilla. (También de la eterna arquitectura del bar, insisto, a ver si cuela.) Qué más voy a desear, y a decir... 